\title{
The ToOl Wear ObServation OF Milling ToOls in High FEED MACHINING OF HARDENEd STEELS
}

\author{
František Jurina, Tomáš Vopát, Marcel Kuruc \& Vladimír Šimna
}
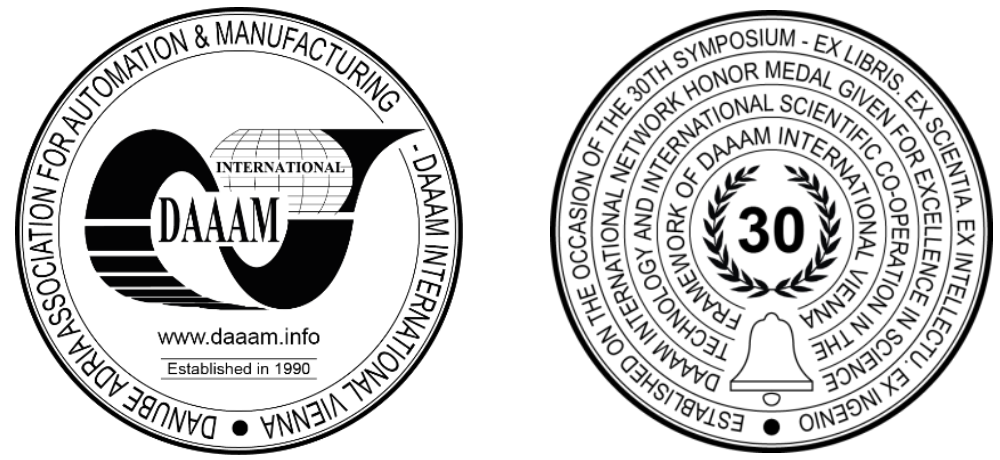

This Publication has to be referred as: Jurina, F[rantisek]; Vopat, T[omas]; Kuruc, M[arcel] \& Simna, V[ladimir] (2019). The Tool Wear Observation of Milling Tools in High Feed Machining of Hardened Steels, Proceedings of the 30th DAAAM International Symposium, pp.0753-0757, B. Katalinic (Ed.), Published by DAAAM International, ISBN 978-3-902734-22-8, ISSN 1726-9679, Vienna, Austria

DOI: $10.2507 / 30$ th.daaam.proceedings.103

\begin{abstract}
The paper deals with the issue of high feed machining of the hardened steels the aim was to determine dependence of the tool wear on material removed volume. The milling tools with cemented carbide cutting inserts had a cutting edge angle $20^{\circ}$ and theoretical nose radius $1.6 \mathrm{~mm}$ designed for milling with high values of feed. The tested workpiece material was DIN X38CrMoV53, equivalent to W.Nr. 1.2367, tool steel that was hardened and tempered what resulted in a hardness of 54 HRC. The tool wear was observed on the Zoller Genius 3s universal measuring device. The flank wear was measured with respect to the material removed volume when depth of cut and feed were varied. The flank wear was dominant tool wear type. Over the flank wear value of $0.3 \mathrm{~mm}$, too large edge chipping and insert breakage were observed due to excessive wear. The highest material removed volume was observed when depth of cut of $0.5 \mathrm{~mm}$ and the lowest feed of $0.3 \mathrm{~mm}$ were used.
\end{abstract}

Keywords: Cutting; High feed machining; Tool wear; Tool life; Difficult-to-cut

\section{Introduction}

High feed milling is a milling method that allows increasing efficiency of the machining compared with conventional methods. High feed milling is very effective roughing method for copy milling of free form surfaces for creating moulds and dies. The obtained results in the article [1] presents that a high speed milling process in which tool path describes a quarter circle in each tool path is able to produce adequate roughness values for moulds and dies made of hardened tool steel AISI D6.

Schulz [2] suggested two different turn-milling operations and performed the experiments to identify cutting parameters that result good surface. In another article [3], Schulz showed experimentally the effect of turn-milling process parameters on the tool life and surface quality [4].

The HFM process causes an insertion of compressive residual stresses with an anisotropic state in their principal stresses. Accordingly, the in-plane stress measured transverse to the milling direction was found to achieve higher stresses values [5]. The article compared the various methods of residual stress analysis after high feed milling. Simple axial 
measurement proved monitoring of residual stress states in very thin layers [6]. The paper [7] presents an experimental investigation of the effect of cutting parameters on the surface integrity such as surface roughness, surface residual stresses and surface microhardness in high-speed milling of 16Co14Ni10Cr2Mo ultrahigh strength steel.

In the article [8], three different types of high-feed milling tools were selected to process different types of surfaces structures. Depending on the tool geometry and the parameter values used for machining, the characterization of the surface structure was adjusted. Depending on the lower lead angle $\alpha$, more material was cut from the subsequent cutting teeth, which leads to a smoother surface structure. Besides the lead angle $\alpha$, the tool geometry also has an influence on the milled surface structure.

The work [9] examines the sustainability effect of the coating thickness of mono-layered and multi-layered coatings while machining at varying cutting speeds and feed rates. The mono-layered AlCrN coated tools performed satisfactorily at lower feed rate but as the feed rate increased, the mono-layer structure of AlCrN coating failed due to the increase of machining forces and higher temperature generation which is evident from the various machining responses evaluated for AlCrN coated tools. The article [10] deals with a determination of the influence of a cutting edge preparation on the quality and wear resistance of coated cutting tools. The tool life test of cutting inserts was carried out for verification of the influence of surface treatment on the wear resistance of cutting inserts during the milling process. The influence of cutting edge radius on the force load [11] and the surface roughness [12] in machining the nickel based alloy was determined. In the research [13] tool life during the machining of very hard material (DIN X210Cr12) was determined.

Experiments in [14] show that the feed rate adjustment method has weak control on the milling force and tool vibrations, therefore, the tool wear is relatively big, and it is easy for the tool to be fatigued and damaged. However, trochoidal milling method is more effective at milling force control, reduction of tool vibrations, and tool wear. By increasing the axial depth of cut, the milling efficiency and tool wear of trochoidal milling method is better than the feed rate adjustment method. In the article [15] in the hard turning process, the varied cutting edge geometries were tested at different cutting conditions to highlight the combinational complexity of cutting edges and cutting condition in producing surface roughness and residual stresses. The study in [16] was focused on the feasibility of simulating discontinuous chips in high speed hard machining.

The high-feed milling offers a new approach to produce extensive deterministic structures at short process times. The structural geometry results from the variation of different milling strategies, tool geometries, tilt angles, and feed per tooth. It can be stated that milling with high-feed tools is a promising method for affecting the material flow during forming processes by structuring the forming-tool surface. The durability of high-feed tools due to the special shape of the cutting edge make them particularly interesting for structuring already tempered semi-finished tools [17]. The comparison of high feed machining with conventional milling in terms of dimension accuracy and productivity is presented in [18].

In this article, the influence of cutting parameters on the tool wear are investigated during the high feed machining process when depth of cut and feed were varied and cutting speed kept constant.

\section{Experimental details}

The BNGX 10T308SR-HM cutting inserts and 35E6R043M16-SBN10-C toolholder were selected for this research. The chuck DIN 69871 (SK40) was clamped into the spindle of vertical machining centre. Designation of HM for cutting inserts represents geometry of cutting edge with negative bevel of $14^{\circ}$ and dimension of $0.09 \mathrm{~mm}$ that is appropriate for machining hard materials (Fig. 1). The cutting inserts for high feed milling use typical geometry with theoretical tool nose radius as in this case where the value of theoretical tool nose radius was $1.6 \mathrm{~mm}$. Tested cutting tool material was coated cemented carbide. The tool geometry of cemented carbide cutting insert can be seen in Table 1.

\begin{tabular}{|c|c|c|c|c|c|c|}
\hline diameter & $\boldsymbol{\kappa}_{\mathbf{r}}$ & $\boldsymbol{\alpha}$ & $\boldsymbol{\gamma}_{\mathbf{P}}$ & $\boldsymbol{\gamma}_{\mathbf{f}}$ & $\mathbf{a}_{\mathbf{p} \text { max }}$ & no. of teeth \\
\hline $35 \mathrm{~mm}$ & $20^{\circ}$ & $0^{\circ}$ & $-10^{\circ}$ & $-7,5^{\circ}$ & $1 \mathrm{~mm}$ & 6 \\
\hline
\end{tabular}

Table 1. BNGX 10T308SR-HM cemented carbide cutting insert (CCI) geometry and wedge angles
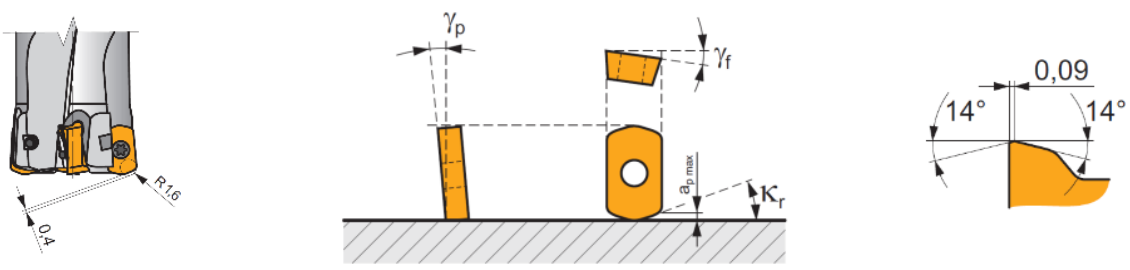

Fig. 1. BNGX 10T308SR-HM cemented carbide cutting insert (CCI) geometry and wedge angles [19]

In this experiment, the tested workpiece material was tool steel of DIN EN X38CrMoV5-3 (W. NR. 1.2367) grade. Chemical composition of material is shown in Table 2. The hardness after hardening and tempering was 54 HRC. 


\begin{tabular}{|c|c|c|c|c|c|c|}
\hline Element & C & Si & Mn & Cr & Mo & V \\
\hline wt. $\%$ & $0.35-0.40$ & $0.30-0.50$ & $0.30-0.60$ & $4.70-5.20$ & $2.70-3.30$ & $0.40-0.70$ \\
\hline
\end{tabular}

Table 2. Chemical composition of EN-GJL-250 gray cast iron material [20]

The cemented carbide cutting inserts were tested on the vertical machining centre. The machining process was cooled with compressed air. The tested workpiece material was clamped by magnetic clamping system as seen in Fig. 2 a. The toolpaths were generated in CAM software with respect to the shape of die (Fig. 2b). The helical milling strategy with constant value of depth of cut was used in the cutting test. The milling strategy represent real cutting conditions for machining free for surfaces such as machining dies and moulds. In the experiment, the following combination of cutting parameters were used (Table 3). The tool wear was measured on Zoller Genius 3s universal measuring machine

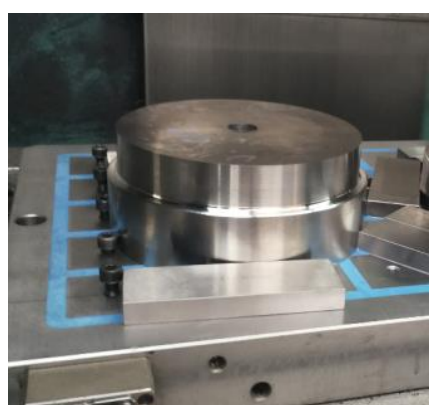

a)

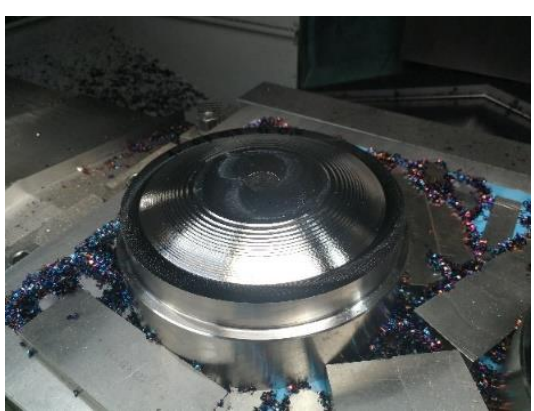

b)

Fig. 2. Tested workpiece material (a) before cutting test and (b) after

\begin{tabular}{|c|c|c|c|c|}
\hline \multirow{2}{*}{ Cutting parameter } & \multicolumn{4}{|c|}{ Test no. } \\
\cline { 2 - 5 } & $\mathbf{1}$ & $\mathbf{2}$ & $\mathbf{3}$ & $\mathbf{4}$ \\
\hline Cutting speed $v_{c}(\mathrm{~m} / \mathrm{min})$ & 100 & 100 & 100 & 100 \\
\hline Depth of cut $a_{p}(\mathrm{~mm})$ & 0.5 & 0.5 & 0.3 & 0.3 \\
\hline Feed per tooth $f(\mathrm{~mm})$ & 0.5 & 0.3 & 0.83 & 0.5 \\
\hline Feed speed $v_{f}(\mathrm{~mm} / \mathrm{min})$ & 2728 & 1637 & 4545 & 2728 \\
\hline Radial depth of cut $a_{e}(\mathrm{~mm})$ & 20 & 20 & 20 & 20 \\
\hline
\end{tabular}

Table 3. Cutting parameters

\section{Results}

The flank wear was measured with respect to the material removed volume (MRV) whereas high feed milling belongs to roughing strategy. Therefore, the aim was to determine dependence of the tool wear on MRV. The flank wear was measured because it was dominant tool wear type. The flank wear criterion was $V B_{K}=0.3 \mathrm{~mm}$ because too large edge chipping (Fig. 4a) and insert breakage (Fig. 4b) were observed over these value. It was caused by excessive wear. Uniform wear rate was observed up to the flank wear value of $0.3 \mathrm{~mm}$ (Fig. 3 on the left) where tool material was removed from the cutting edge. For this reason, the cutting insert thickness was progressively lower and the real cutting edge was moved (Fig. 3b on the right).
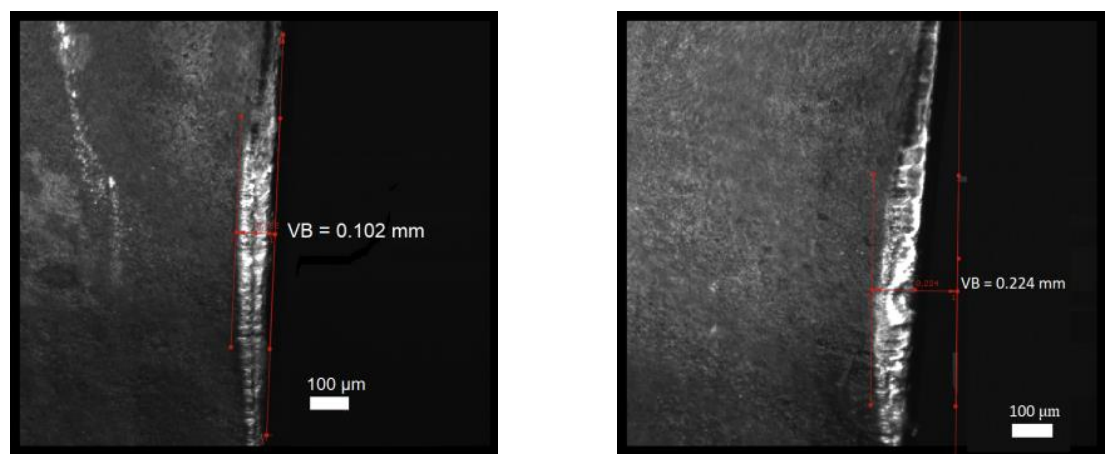

Fig. 3. Flank wear development in steady state region 


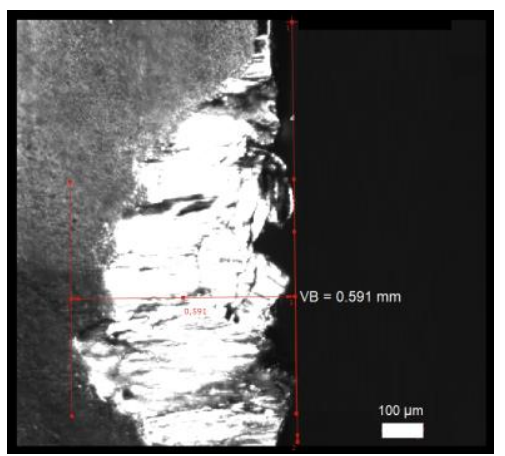

a)

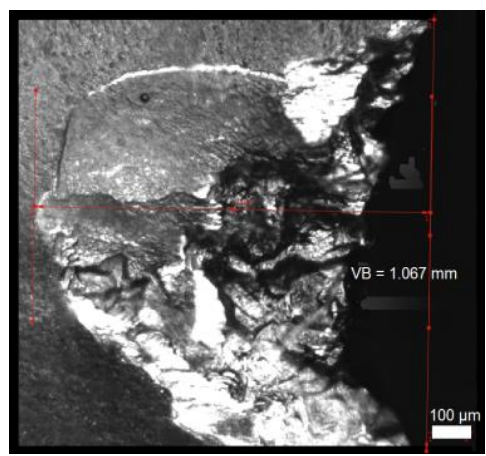

b)

Fig. 4. Tool wear types over the flank wear value of $0.3 \mathrm{~mm}$ (a) edge chipping and (b) insert breakage

The graph in Fig. 5 shows MRV for particular combination of cutting parameters until cemented carbide cutting inserts reached flank wear criterion. Since, six cemented cutting carbide inserts were used in one toolholder during the cutting test, the average values of MRV were calculated and inserted to the graph. Standard deviations were also calculated and subsequently the error bars were inserted to the graph. The highest MRV was observed in test no. 2 when depth of cut of $0.5 \mathrm{~mm}$ and the lowest feed of $0.3 \mathrm{~mm}$ were used.

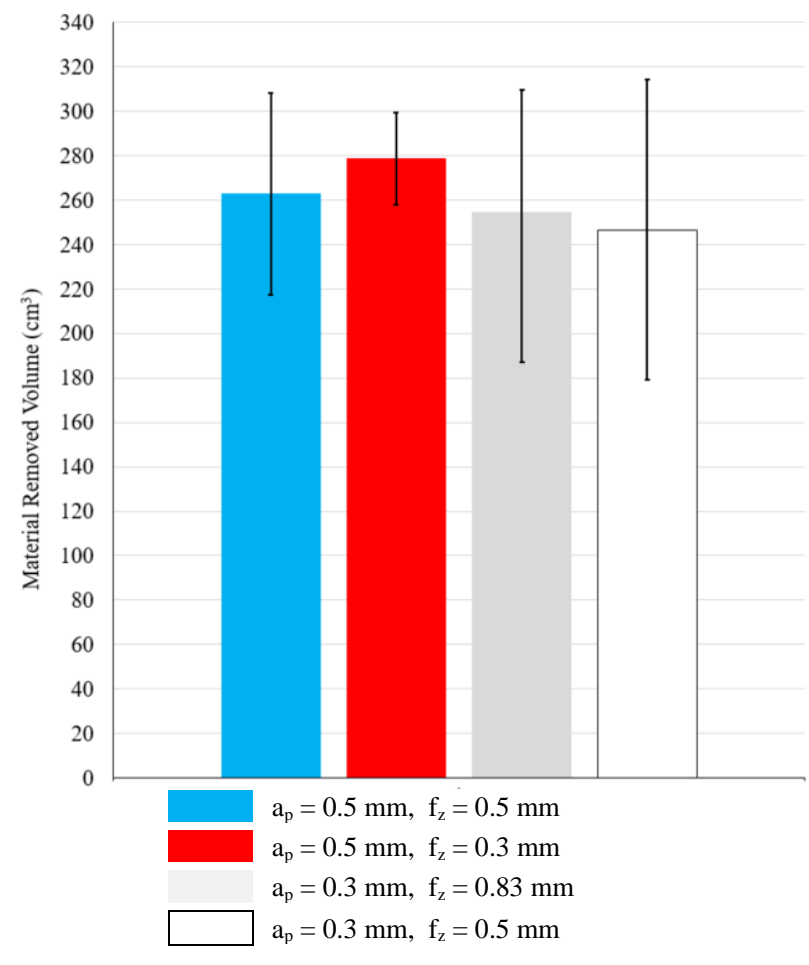

Fig. 5. Graph of material removed volume with respect to the cutting parameters

\section{Conclusion}

In this article, the observation of tool wear during the high feed machining of hardened steel was performed. The cutting inserts for high feed milling used typical geometry with theoretical tool nose radius. In this experiment, the tested workpiece material was tool steel of DIN EN X38CrMoV5-3 (W. NR. 1.2367) grade. The hardness after hardening and tempering was 54 HRC.

The aim was to determine dependence of the tool wear on material removed volume. The flank wear was the dominant tool wear type. If the flank wear value of $0.3 \mathrm{~mm}$ was exceeded too large edge chipping and insert breakage were observed. It was caused by excessive tool wear. The flank wear development was relatively linear up to the value of $0.3 \mathrm{~mm}$. The highest material removed volume was observed in test when depth of cut of $0.5 \mathrm{~mm}$ and the lowest feed of $0.3 \mathrm{~mm}$ were used until the cemented carbide cutting inserts reached the tool wear criterion.

In the future work, authors are going to focus on investigation of issue of cutting edge microgeometry during the high feed machining the difficult-to-cut materials. 


\section{Acknowledgments}

This work was supported by the Scientific Grant Agency of the Slovak Republic under the grant no. 1/0097/17 and the Slovak Research and Development Agency of the Slovak Republic under the Contract no. APVV-16-0057.

Authors are grateful to Pre-Tech Indutries, s.r.o., that participated in this research. Authors are also grateful to Branislav Augustovič, who assisted during the experiment.

\section{References}

[1] Castanhera, I. da C. \& Diniz, A. E. (2016). High Speed Milling of Hardened Steel Convex Surface, Procedia Manufacturing, Vol. 5, 220-231. doi:10.1016/j.promfg.2016.08.020

[2] Schulz, H. \& Spur, G. (1990). High Speed Turn-Milling - A New Precision Manufacturing Technology for the Machining of Rotationally Symmetrical Workpieces, CIRP Annals, Vol. 39, No. 1, 107-109. doi:10.1016/S00078506(07)61013-0

[3] Schulz, H. \& Kneisel, T. (1994). Turn-Milling of Hardened Steel - an Alternative to Turning, CIRP Annals, Vol. 43, No. 1, 93-96. doi:10.1016/S0007-8506(07)62172-6

[4] Comak, A. (2017). Mechanics of turn-milling operations, International Journal of Machine Tools and Manufacture, Vol. 121, 2-9. doi:10.1016/J.IJMACHTOOLS.2017.03.007

[5] Tillmann, W.; Hagen, L.; Stangier, D.; Paulus, M.; Tolan, M.; Sakrowski, R.; Biermann, D. \& Freiburg, D. (2019). Microstructural characteristics of high-feed milled HVOF sprayed WC-Co coatings, Surface and Coatings Technology, Vol. 374, 448-459. doi:10.1016/J.SURFCOAT.2019.06.012

[6] Zauskova, L.; Czan, A.; Sajgalik, M.; Drbul, M. \&Rysava, Z. (2017). Triaxial Measurement of Residual Stress After High Feed Milling Using X-ray Diffraction, Procedia Engineering, Vol. 192, 982-987. doi:10.1016/j.proeng.2017.06.169

[7] Zhenchao, Y.; Yang, X.; Yan, L.; Jin, X. \& Quandai, W. (2018). The effect of milling parameters on surface integrity in high-speed milling of ultrahigh strength steel, Procedia CIRP, Vol. 71, 83-88. doi:10.1016/j.procir.2018.05.076

[8] Tillmann, W.; Stangier, D.; Laemmerhirt, I. A.; Biermann, D. \& Freiburg, D. (2016). Investigation of the tribological properties of high-feed milled structures and Cr-based hard PVD-coatings, Vacuum, Vol. 131, 5-13. doi:10.1016/j.vacuum.2016.05.024

[9] Kumar, C. S. \& Patel, S. K. (2018). Investigations on the effect of thickness and structure of AlCr and AlTi based nitride coatings during hard machining process, Journal of Manufacturing Processes, Vol. 31, 336-347. doi:10.1016/J.JMAPRO.2017.11.031

[10] Zlamal, T.; Mrkvica, I.; Szotkowski, T. \& Malotova, S. (2019). The Influence of Surface Treatment of PVD Coating on Its Quality and Wear Resistant, Coatings, Vol. 9, No. 7, 439. doi:10.3390/coatings9070439

[11] Hronek, O.; Zetek, M. \& Bakša, T. (2018). The influence of cutting edge radius on force load when milling inconel 718, B. Katalinic (Ed.), Proceedings of the 29th DAAAM International Symposium, 822-828, ISBN 978-3-90273420-4. doi:10.2507/29th.daaam.proceedings.119

[12] Hronek, O. \& Zetek, M. (2017). The influences of cutting edge radius on surface roughness when milling nickel alloy, B. Katalinic (Ed.), Proceedings of the 28th DAAAM International Symposium, DAAAM International, 10371043, ISBN 978-3-902734-11-2. doi:10.2507/28th.daaam.proceedings.144

[13] Bakša, T.; Kroupa, T.; Hanzl, P. \& Zetek, M. (2015). Durability of Cutting Tools during Machining of Very Hard and Solid Materials, Procedia Engineering, Vol. 100, 1414-1423. doi:10.1016/j.proeng.2015.01.511

[14] Shixiong, W.; Wei, M.; Bin, L. \& Chengyong, W. (2016). Trochoidal machining for the high-speed milling of pockets, Journal of Materials Processing Technology, Vol. 233, 29-43. doi:10.1016/J.JMATPROTEC.2016.01.033

[15] Varela, P. I.; Rakurty, C. S. \& Balaji, A. K. (2014). Surface Integrity in Hard Machining of 300M Steel: Effect of Cutting-edge Geometry on Machining Induced Residual Stresses, Procedia CIRP, Vol. 13, $288-293$. doi:10.1016/j.procir.2014.04.049

[16] Guo, Y. B. \& Yen, D. W. (2004). A FEM study on mechanisms of discontinuous chip formation in hard machining, Journal of Materials Processing Technology, Vols 155-156, 1350-1356. doi:10.1016/J.JMATPROTEC.2004.04.210

[17] Hense, R.; Wels, C.; Kersting, P.; Vierzigmann, U.; Löffler, M.; Biermann, D. \& Merklein, M. (2015). High-feed milling of tailored surfaces for sheet-bulk metal forming tools, Production Engineering, Vol. 9, No. 2, $215-223$. doi:10.1007/s11740-014-0597-0

[18] Kuruc, M.; Vozár, M.; Šimna, V.; Vopát, T.; Hrušecký, R.; Milde, J.; Buranský, I.; Necpal, M. \& Peterka, J. (2018). Comparison of high feed machining with conventional milling in terms of dimension accuracy and productivity, B. Katalinic (Ed.), Proceedings of the 29th DAAAM International Symposium, DAAAM International, $426-434$. doi:10.2507/29th.daaam.proceedings.063

[19] Dormenr Pramet. (2017). New products 2017.2, p.84

[20] JZK Bučovice. (n.d.). Tool Steels Charecteristics, from https://www.jkz.cz/en/produkty/nastrojove-oceli/pro-praceza-tepla/w-nr-12367/ 